\title{
AMOR E ADOLESCÊNCIA NOS DIAS DE HOJE: UMA ANÁLISE SISTÊMICO-FUNCIONAL
}

TODAY'S LOVE AND ADOLESCENCE: A SYSTEMIC-FUNCTIONAL ANALYSIS

Graziela Fachim (UFSM)

grazi_f93@hotmail.com

\begin{abstract}
RESUMO: O presente trabalho tem como objetivo investigar a relação do adolescente com o sentimento do amor através de suas escolhas léxico-gramaticais e semântico-discursivas, considerando os preceitos da Linguística Sistêmico-Funcional - mais precisamente, o sistema de transitividade. O corpus de pesquisa é constituído por 25 relatos pessoais produzidos por adolescentes entre 17 e 18 anos de uma escola pública de ensino médio do interior do estado do RS. Os resultados evidenciaram que o papel dos jovens ainda está muito mais ligado à categoria de Recebedor (56\%) - aquele que é afetado por esse sentimento, sendo o amor recebido, na maioria das vezes, sinalizado como Fenômeno das orações mentais perceptivas, indicando que os jovens sentem-se amados por outras pessoas - do que à categoria de Amante (44\%), na qual o é sujeito responsável por amar outro alguém ou algo, resultado de ser o Experienciador das orações mentais emotivas.
\end{abstract}

PALAVRAS-CHAVE: Linguística Sistêmico-Funcional; sistema de transitividade; amor; adolescência.

\begin{abstract}
This paper aims to investigate the relationship between teenagers and the feeling of love through their lexical-grammatical and semantic-discursive choices, considering the principles of the Transitivity System of Systemic-Functional Linguistics. The research corpus consists of 25 personal reports produced by teenagers between the ages of 17 and 18 from a public high school in the countryside of the state of Rio Grande do Sul, Brazil. The results showed that the teenagers' role is still much more connected to the Receiver category (56\%), that is, the one affected by this feeling. The love received, in most cases, is signaled as the Phenomenon of perceptive mental clauses, indicating that teenagers feel loved by other people, rather than the Lover category (44\%), in which the subject is responsible for loving someone else or something, the result of being the Senser of emotive mental clauses.
\end{abstract}

KEYWORDS: Systemic Functional Linguistics; Transitivity System; Love; Adolescence. 


\section{Considerações iniciais}

A emoção é parte integrante da vida. Todos os dias, reagimos a situações com diferentes sentimentos: ficamos felizes, tristes, assustados, (in)seguros. As emoções são recursos de expressão com os quais nascemos. Vamos incorporando-os psicologicamente a partir do nosso primeiro dia de vida (PAINTER, 2003). Podemos externalizar essas emoções através de reações comportamentais, seja ao sorrirmos, seja ao chorarmos, bem como através da língua. Nessa perspectiva, argumenta-se que a maneira como expressamos e falamos sobre nossas emoções é o que nos torna humanos, e que o estudo desse discurso prova "uma das mais fundamentais características humanas" (BEDNAREK, 2008, p.15).

Sendo assim, emoção e linguagem estão em conexão, uma vez que o sistema da emoção afeta a performance da língua (BAMBERG, 1997). É através dela que tentamos nos fazer entender e buscamos compreender nossas próprias emoções. A língua é, portanto, uma parte essencial dos fenômenos complexos da experiência do indivíduo (HALLIDAY, 2002). É com base nessa representação e na interpretação das emoções que avaliamos, interagimos e modificamos nossas respostas, sejam elas comportamentais ou linguísticas. As emoções têm um forte impacto na comunicação, frequentemente interrompendo e gerando novos objetivos e planos, tendo consequências importantes para a interação social (SCHERER, 2005).

Uma das emoções a que estamos expostos constantemente é o amor, seja por produções artísticas, como canções românticas, novelas, filmes, seriados, livros, ou por conversas informais com os pais, amigos(as) e namorados(as). Esse contato diário molda nossa própria forma de amar (PLANALP, 1999). O amor que sentimos tende, portanto, a se encaixar, de maior ou menor maneira, dentro das expetativas da cultura dominante na qual estamos inseridos (BEDNAREK, 2008). Considera-se, então, que a comunicação do amor "é um aspecto importante das relações interpessoais", uma vez que somos moldados de acordo com nossa cultura e experiências de vida (WILKINS; GAREIS, 2006, p.52). O estudo da expressão do amor, uma vez que se encontra no domínio das emoções, é capaz de revelar aspectos da vida moral e cultural em que o indivíduo em questão está inserido, evidenciando também os valores estruturais e culturais que estão sendo reproduzidos e negociados ao comunicarmos nossas emoções (WILKINS; GAREIS, 2006).

Com o objetivo de identificar a relação do adolescente dos dias de hoje com o sentimento do amor foram selecionadas três turmas de $3^{\circ}$ ano do ensino médio de uma escola pública de um município no interior do estado do RS. A faixa etária dos participantes varia de 17 a 18 anos. A escolha dessa faixa etária dá-se também pelo fato de ser durante a Organon, Porto Alegre, v. 36, n. 71, p. 448-463, jan./jun. 2021. 
adolescência que os indivíduos atravessam uma fase de amadurecimento, descobertas e controle das próprias emoções, uma vez que é nesse período que a personalidade do adolescente flui e transmuta-se (VYGOTSKY, 1984). Com esta análise, foi possível verificar a reflexão desses jovens sobre esse sentimento tanto consigo mesmos, bem como com terceiros. Foi possível ainda identificar de que maneira eles fazem uso da linguagem para “materializarem” o que estão sentindo, uma vez que essa pode ser uma tarefa difícil.

Em se tratando da temática amor, fez-se necessário, para nossa pesquisa, um breve panorama geral desse tema sob a ótica da Psicologia Cognitiva e Histórico-Cultural, a fim de darmos conta dos participantes, e da Linguística Sistêmico-Funcional para abordarmos nosso corpus de análise.

\section{O amor e a adolescência sob a ótica da Psicologia Cognitiva e Histórico-Cultural}

Por sua natureza pessoal e íntima, o amor era considerado impróprio para um estudo empírico (HARLOW, 1958). De acordo com Harlow (1958), esse sentimento é nutrido pela criança junto à sua mãe, sendo também a partir dessa íntima ligação que o indivíduo forma suas respostas afetivas ao longo da vida. Complementa-se mais tarde que, em termos de história individual, nossa capacidade e habilidade de amar são afetadas por nossa experiência de ser amado ao longo da infância (OATLEY, 2004).

É durante a adolescência que os contextos dos quais os jovens fazem parte se ampliam, fazendo com que seja necessária sua participação e assunção a novos papéis sociais. Cada novo papel será de suma importância e trará consequências para seu desenvolvimento. A cultura e a experiência no meio social atuam no desenvolvimento do indivíduo através dos sistemas simbólicos aos quais ele foi exposto, sendo a linguagem o sistema mediador desses símbolos (VYGOTSKY, 1984). É através das palavras que se torna possível o contato do indivíduo com o mundo, bem como com a sua própria consciência, dando-lhe a oportunidade de expressar seus valores e posições, refletindo também sua realidade (VYGOTSKY, 1984; XAVIER; NUNES, 2015).

Portanto, é a partir da interação social, de determinados comportamentos e de produtos culturais que os indivíduos modelam e (re)constroem seus pensamentos e significações (OLIVEIRA, 1997). Assim, considera-se a interação dos seres humanos como um fator importante no desenvolvimento individual, dando destaque ao conceito da zona de desenvolvimento proximal de Vygotsky (XAVIER; NUNES, 2015). Partindo da teoria vygotskyana, temos o desenvolvimento da criança sob três diferentes zonas: a) zona de 
desenvolvimento real: caracterizada pelas funções já adquiridas pelos indivíduos, a qual permite a solução de problemas pela criança de forma independente; b) zona de desenvolvimento potencial: referente àquilo que a criança pode vir a saber, ou seja, àquilo que ela ainda não faz, mas tem condições de realizar dadas as condições necessárias; c) zona de desenvolvimento proximal: é o processo que separa a zona de desenvolvimento real e potencial, ou seja, é o caminho que o indivíduo deve percorrer sob a orientação de um adulto ou companheiro capaz para desenvolver funções que estão em processo de amadurecimento (OLIVEIRA, 1997; XAVIER; NUNES, 2015).

Considerando que somos seres resultantes do nosso meio, afetados pelas relações e pelas experiências que vivemos, temos como resultado desse impacto o desenvolvimento das emoções. É somente por conta da capacidade do indivíduo de formular abstrações acerca de suas experiências que é possível o desenvolvimento do sentimento (XAVIER; NUNES, 2015). Para os autores que seguem os conceitos da Psicologia Histórico-Cultural, como resultado final da adolescência, tem-se uma maior estabilidade das relações afetivas, uma vez que a maior participação no meio social faz com que o adolescente seja capaz de expandir suas fronteiras do mundo e de suas experiências.

\section{O amor e a língua sob a ótica da Linguística Sistêmico-Funcional}

$\mathrm{O}$ aumento do interesse em pesquisas que abordam a temática do amor na linguística surge da necessidade do estudo da conexão da linguagem com a consciência e com o pensamento humano, bem como sua cultura (PAVENKOV, 2014). O mesmo autor, ao descrever as diferentes abordagens de estudo do discurso do amor, afirma que a língua é um dos meios que torna possível expressar aspectos verbais e não verbais da nossa consciência e da nossa personalidade, sendo o amor muito mais do que apenas um elemento básico da língua do indivíduo, mas também aquele que tem o poder de expressar aspectos culturais nos quais os indivíduos estão inseridos.

Considerando tal temática sob a perspectiva da Linguística Sistêmico-Funcional (doravante LSF), que é a principal base teórica para esta pesquisa, a linguagem está construindo e, ao mesmo tempo, pondo em prática nossas relações com as pessoas e com o que está a nossa volta (HALLIDAY, 1985). Sendo assim, é através dela que podemos analisar a representação do mundo (metafunção ideacional), de como interações são feitas (metafunção interpessoal) e de como elas são organizadas (metafunção textual) (FUZER; CABRAL, 2014). Para LSF, o contexto está sempre determinando as escolhas linguísticas que 
constituem um texto, e cabe ao escritor/falante selecionar os elementos apropriados para cada situação (FUZER; CABRAL, 2014).

É através da linguagem - metafunção ideacional - que podemos construir nossa realidade, considerando pessoas, lugares, objetos concretos ou abstratos, eventos e circunstâncias (BUTT et al, 2000). Todos esses elementos da experiência humana realizam-se linguisticamente através da oração e são expressos por meio do sistema de transitividade, sendo o evento representado pelo tipo de processo escolhido, implicando a associação dos papéis dos participantes e de suas configurações (BUTT et al, 2000; EGGINS, 2004).

O ser humano representa suas experiências de mundo através de três principais processos, denominados materiais, mentais e relacionais; e de outros três processos secundários, chamados de comportamentais, verbais e existenciais (MARTIN; MATTHIESSEN; PAINTER, 2010; FUZER; CABRAL, 2014). Os limites entre os processos principais e secundários são tênues, uma vez que os secundários possuem características pertencentes aos primários.

Os processos materiais são responsáveis pela construção de significados e representações do tipo "fazer" e "acontecer", estabelecendo assim o fluxo de eventos e as mudanças do mundo (HALLIDAY; MATTHIESSEN, 2004; EGGINS, 2004). Os processos materiais envolvem um ou mais participantes e podem ser realizados por grupos nominais responsáveis por praticarem a ação, os quais denominamos de Ator, ou aqueles que são impactados por essas ações, chamados de Meta.

Os processos mentais, responsáveis por representarem a nossa experiência do mundo da consciência, nossas reações mentais de pensamentos, sentimentos e percepções (EGGINS, 2004), podem ser classificados como cognitivos (pensar), desiderativos (querer), emotivos (sentir) e perceptivos (ver) (MARTIN; MATTHIESSEN; PAINTER, 2010). As orações mentais mudam a percepção que se tem da realidade, construindo, assim, o processo da própria consciência do falante (FUZER; CABRAL, 2014). Uma característica das orações mentais é que seus participantes, denominados Experienciadores, devem ser humanos, ou personificações de objetos e animais, que tenham a capacidade de pensar, desejar, sentir ou perceber (EGGINS, 2004). O complemento desse processo chama-se Fenômeno, geralmente realizado por grupos nominais e orações não finitas, responsáveis por representar aquilo que é pensado, sentido, percebido ou desejado (FUZER; CABRAL, 2014).

Os processos relacionais são responsáveis por caracterizar, descrever e identificar seus participantes (HALLIDAY; MATTHIESSEN, 2004; BUTT et al., 2000). As orações relacionais podem ser divididas em dois tipos: relacionais atributivas, as quais relacionam um Organon, Porto Alegre, v. 36, n. 71, p. 448-463, jan./jun. 2021. 
participante a suas características ou descrições; ou relacionais identificativas, as quais relacionam um participante a uma identificação, papel ou significado (BUTT et al., 2000). O participante das orações relacionais pode, portanto, variar, sendo Portador e Atributo ou Identificador e Identificado, de acordo com o tipo e o modo da oração (HALLIDAY; MATTHIESSEN, 2004; FUZER; CABRAL, 2014).

Quanto aos processos secundários, temos os verbais, representados pelos processos de "dizer", podendo ser indicados através de uma atividade como falar, conversar, elogiar e insultar, ou através de semiose, ao indicar e dar comandos a alguém (MARTIN; MATTHIESSEN; PAINTER, 2010; FUZER; CABRAL, 2014). Os processos comportamentais são responsáveis pela representação dos comportamentos tipicamente humanos, sejam eles psicológicos ou fisiológicos, como respirar, tossir, sonhar, sorrir (HALLIDAY; MATTHIESSEN, 2004). E, por fim, temos as orações existenciais, representando o que existe ou acontece no mundo a nossa volta. As orações existenciais são realizadas tipicamente pelo verbo "haver" e contêm apenas um participante, denominado Existente (HALLIDAY; MATTHIESSEN, 2004).

Considerando que usamos a linguagem como meio de representação das nossas experiências, sejam elas externas ou internas à nossa consciência, e que modificamos nossa linguagem de acordo com o contexto em que estamos inseridos, salientamos novamente nosso objetivo de investigar a relação do adolescente com o sentimento do amor através de suas escolhas linguísticas. Na próxima seção, apresentamos a metodologia utilizada para o desenvolvimento do trabalho.

\section{Metodologia}

Há diversas maneiras possíveis para se estruturar uma investigação científica, e é de suma importância que os procedimentos escolhidos para a pesquisa prestem-se aos seus propósitos investigativos (MOTTA-ROTH; HENDGES, 2010). A presente pesquisa caracteriza-se como qualitativa-interpretativa com uso de recursos quantitativos e que tem como base a Linguística Sistêmico-Funcional. Cabe à pesquisa qualitativa-interpretativa compreender o mundo social como constituído pelos significados construídos pelo homem e pela interpretação desses significados (GRANDE, 2011). Tal prática interpretativa faz do pesquisador um colecionador de conchas, que reúne pedaços da realidade, envolvendo uma estética de representação como em uma montagem na qual imagens diferentes são sobrepostas para criar um quadro (DENZIN; LINCOLN, 2006). 


\section{A coleta do corpus}

Considerando o propósito de investigar a relação de adolescentes com o sentimento do amor através das escolhas léxico-gramaticais e semântico-discursivas utilizadas em relatos pessoais, buscava-se um contexto no qual essa faixa etária estivesse inserida. Com isso, delimitou-se o contexto escolar. Após a seleção, chegou-se a uma escola estadual de ensino médio localizada em um município no interior do estado do RS, na qual foram escolhidas, juntamente com a ajuda do professor regente de língua portuguesa, três turmas de terceiro ano do ensino médio. Como participantes efetivos da pesquisa, totalizaram-se 25 adolescentes com idades entre 17 e 18 anos.

Primeiramente, como meio de identificação do contexto pessoal do adolescente e como forma de situar a discussão sobre o sentimento do amor, foi desenvolvido um questionário. Nele, apresentam-se um total de seis questões a serem respondidas: duas questões fechadas, a fim de identificar se o jovem já experienciou o sentimento do amor; duas questões mistas, nas quais devem ser identificadas as pessoas com as quais o sentimento do amor foi experienciado; e duas questões abertas, em que é necessário descrever como foram esses momentos.

O segundo instrumento de coleta deu-se pela escritura de um relato pessoal do adolescente acerca de suas experiências amorosas, bem como de sua concepção sobre o conceito do amor. Na elaboração dos relatos, os participantes responderam à seguinte pergunta: "O que é o amor?". Cada discente elaborou seu texto sem determinação de número mínimo ou máximo de linhas e, além de buscarem definir o termo "amor", apontaram momentos em que se sentiram amados e em que fizeram outra pessoa se sentir amada, além de indicarem os participantes desses episódios.

\section{Procedimentos analíticos}

A análise realizada neste estudo baseia-se, como já discutido anteriormente, nos preceitos da LSF. Levando em consideração que o principal foco do linguista sistêmico é analisar as escolhas linguísticas feitas em um determinado contexto e verificar como essas escolhas produzem significados (SANTOS, 2014), os procedimentos analíticos do corpus coletado foram divididos em duas grandes fases.

Em um primeiro momento, realizou-se uma análise do contexto, na qual foram examinados os 25 questionários respondidos, os quais foram codificados e digitalizados de 
acordo com os seguintes procedimentos: a) identificação das situações em que os adolescentes sentiram amor por alguém; b) identificação das pessoas que recebiam o amor dos adolescentes; c) identificação das situações em que os adolescentes sentiram-se amados por alguém; d) identificação das pessoas por quem os adolescentes sentiram-se amados.

Na segunda fase, deu-se início a análise dos relatos (totalizando igualmente 25 textos), a qual tem como objetivo revelar os papéis exercidos pelos adolescentes e sua relação com o sentimento do amor através de suas escolhas léxico-gramaticais e semântico-discursivas. Para tal, o foco da análise léxico-gramatical teve como ponto de partida as orações que contivessem o item "amor" e seus referentes, segundo o sistema de transitividade, sendo elas classificadas quanto aos seus processos, participantes e circunstâncias, para que assim fosse possível revelarmos os papéis assumidos tanto pelos adolescentes, como pelo próprio sentimento do amor (HALLIDAY; MATTHIESSEN, 2004, 2014). Todas as análises apresentadas aqui foram realizadas de forma manual, com checagem de pares, sem o uso de softwares específicos, por escolha da pesquisadora.

\section{Resultados}

\section{Questionários}

Considerando os resultados obtidos através das análises dos questionários quanto às pessoas pelas quais os jovens sentem-se amados, houve a predominância do amor de mãe, com 92\%, seguido do amor de pai, com 84\%. O amor dos amigos aparece na terceira posição, recebendo $76 \%$ das indicações. Em quarta posição, encontra-se o amor recebido pelos avós, com 72\%, seguido do amor dos irmãos, que representam 64\% de indicação. Por fim, temos o amor recebido dos(as) namorados(as), com 54\%, à frente somente da categoria "outros" (40\%), que destacam demais membros da família, "crushes" ou animais de estimação. A relação das pessoas responsáveis por fazerem os participantes sentirem-se amados é apresentada na Figura 1 a seguir.

Ao descreverem brevemente situações em que já se sentiram amados, muitos adolescentes ressaltaram momentos felizes, como poder ser visto no Exemplo 1 (E\#1). Esses momentos foram descritos em $60 \%$ das vezes como demonstrações de carinho, recebimento de presentes e benefícios da presença do outro, tendo até mesmo a presença de animais de estimação como fator indicativo de felicidade. 


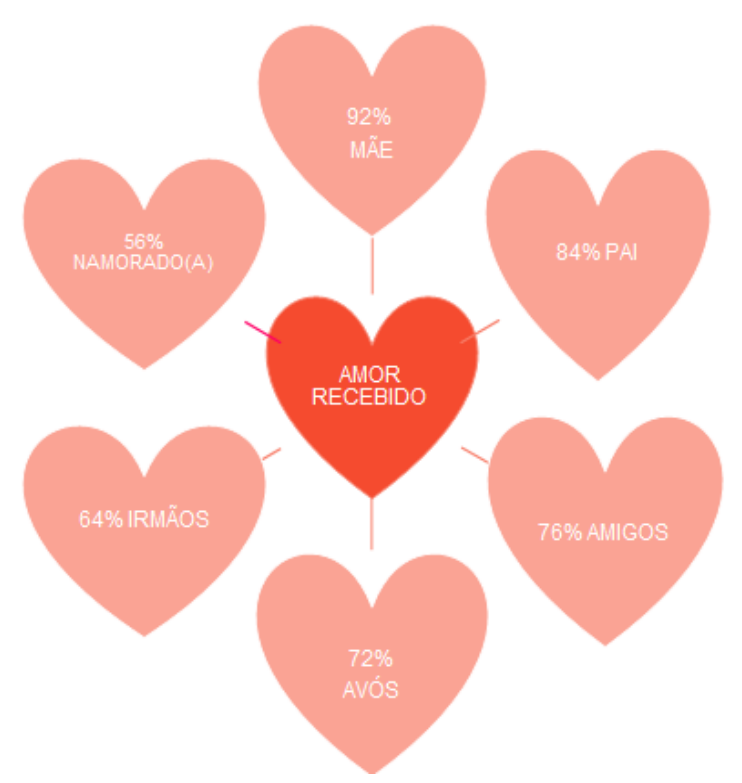

Figura 1 - Aqueles que amam os adolescentes

Fonte: Elaborado pela autora

E\#1 "Demonstração de carinho e cuidado que ela [mãe] tem diariamente comigo".

Contudo, algo que se destacou foi o fato de que, apesar dos momentos felizes, $48 \%$ dos participantes também apresentaram situações de dificuldade, tristeza e necessidade de ajuda ao descreverem como se sentiram amados, como pode ser visualizado no Exemplo 2 (E\#2). Sob o olhar dos adolescentes, ao receberem apoio e ajuda em momentos complicados de suas vidas, foi possível perceber quem estava ao seu lado, sentindo-se, portanto, amados de alguma maneira. De uma forma geral, vale salientar que o amor, para eles, também está relacionado com ajuda e apoio em tempos difíceis.

E\#2 "Nos momentos que mais precisei de apoio, nos momentos que tive crise de pânico e ansiedade principalmente".

Ao indicarem quem são as pessoas às quais seu amor é direcionado, 84\% dos adolescentes indicaram a mãe como a pessoa que mais recebeu esse amor. Em segundo lugar, está o pai, com $72 \%$, seguido dos amigos, com 68\%. Os avós possuem apenas $52 \%$ de indicação, o mesmo índice obtido pela categoria dos(as) namorados(as). A categoria "outros", na qual estão os demais membros da família e os animais de estimação, encontra-se com $24 \%$ de indicação apenas (Figura 2). Quando comparados, o amor recebido e o amor dado apresentam uma diferença percentual, indicando que o segundo acontece em menor frequência do que o primeiro. 


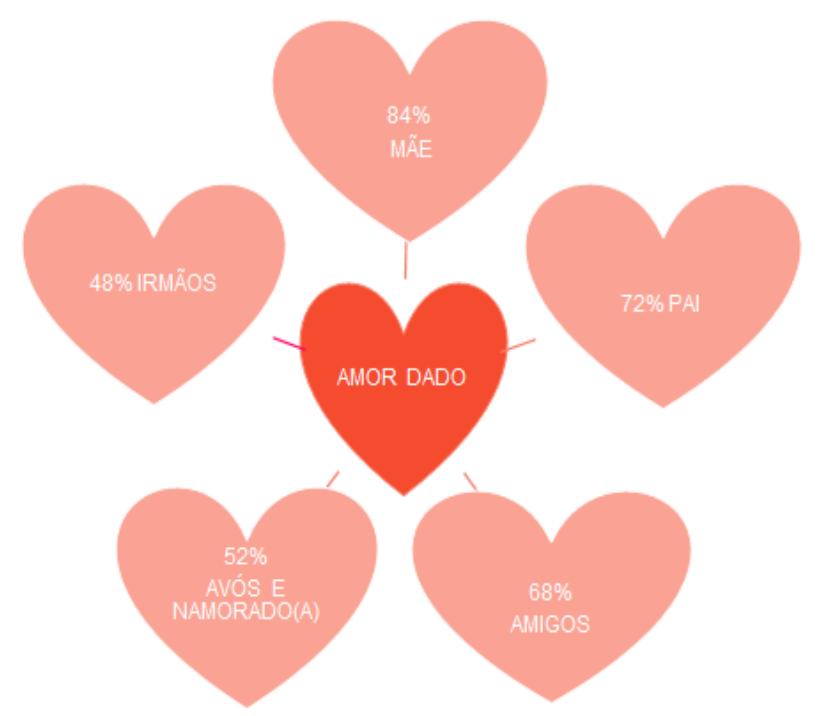

Figura 2 - Aqueles que são amados pelos adolescentes

Fonte: Elaborado pela autora

Ao descreverem as situações em que fizeram essas pessoas sentirem-se amadas, $68 \%$ dos adolescentes indicaram momentos de alegria relacionados com o ato de fazer algo pela pessoa, como abraçar, dar presentes e escrever cartas de amor, como forma de demonstração de tal sentimento. Apesar de apresentarem um índice mais baixo, ainda é possível identificar que $32 \%$ dos adolescentes associam a experiência do amor como resposta a momentos de dificuldade. Os períodos difíceis em que o amor foi experienciado foram relacionados mais uma vez com as atitudes de ajuda e de apoio, como forma de solidariedade. Ambas as situações podem ser observadas no Exemplo 3 (E\#3) e no Exemplo 4 (E\#4) a seguir.

E\#3 "Quando eu abraço a minha mãe e fico elogiando ela".

E\#4 "Num momento onde minha melhor amiga teve uma crise de ansiedade".

Após a descrição do contexto em que esses jovens estão inseridos, das situações e das pessoas que experienciam o amor juntamente com eles, deu-se início às análises dos relatos pessoais.

\section{Relatos Pessoais}

O item léxico-gramatical "amor” e seus referentes foram encontrados em 302 das 371 orações dos 25 relatos pessoais obtidos na coleta. Ao descreverem o sentimento do amor, os adolescentes utilizaram em grande maioria orações relacionais, com $57 \%$ de ocorrência entre os processos utilizados (Figura 3). Esse alto índice é explicado pelo fato de os processos 
relacionais representarem o mundo em termos de suas características e identidades (HALLIDAY; MATTHIESSEN, 2004; FUZER; CABRAL, 2014), e pelo objetivo dos alunos em definir o que é o amor.

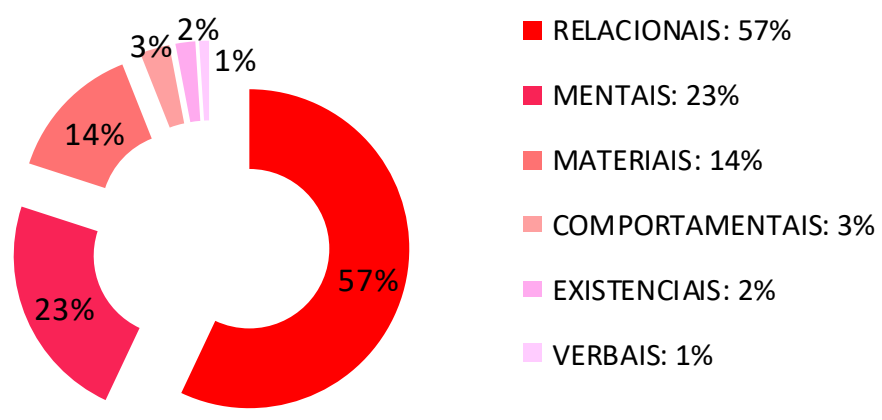

Figura 3 - Tipos de oração

Fonte: Elaborado pela autora

Considerando as orações relacionais, os adolescentes utilizam quase que de forma igualitária tanto orações relacionais identificativas (53\%), quanto orações relacionais atributivas (47\%). Isso se dá pela tentativa dos jovens de conceituar o sentimento do amor, atribuindo-lhe também características, uma vez que as orações identificativas atribuem a uma entidade uma identidade determinada, ao passo que as orações relacionais atributivas as constroem através de características comuns à sua classe (HALLIDAY; MATTHIESSEN, 2004; FUZER; CABRAL, 2014).

O que se destacou ao longo das análises foi que apenas $42 \%$ das orações relacionais identificativas foram construídas com um Identificador composto por um nome juntamente com um artigo definido, como pode ser observado no Exemplo 5 (E\#5). Foi possível encontrar 58\% de orações encaixadas, nas quais o Identificador é realizado por um outro processo ou pela conjunção temporal "quando", como no Exemplo 6 (E\#6). Uma oração encaixada funciona dentro de uma estrutura de grupo, que, por sua vez, funciona na estrutura da oração (HALLIDAY; MATTHIESSEN, 2014). Essas orações no papel de Identificador podem ser consideradas orações encaixadas expansivas de intensificação, uma vez que esse tipo de oração intensifica/realça o significado de algo ao qualificá-lo com referências a um tempo, a um lugar, a uma maneira, a uma causa ou a uma condição (HALLIDAY; MATTHIESSEN, 2014). 


\begin{tabular}{|c|c|c|c|}
\hline \multirow{2}{*}{ E\#5 } & O amor & É & o maior sentimento $[\ldots]$ \\
\cline { 2 - 4 } & Identificado & p. relacional identificativo & Identificador \\
\cline { 2 - 4 } & \multicolumn{3}{|c|}{ ORAÇÃO RELACIONAL IDENTIFICATIVA } \\
\hline
\end{tabular}

\begin{tabular}{|c|c|c|c|}
\hline \multirow{2}{*}{ E\#6 } & O amor & É & [[fazer [a pessoa] feliz]] \\
\cline { 2 - 4 } & Identificado & $\begin{array}{c}\text { p. relacional } \\
\text { identificativo }\end{array}$ & Identificador \\
\cline { 2 - 4 } & \multicolumn{2}{|c|}{ ORAÇÃO RELACIONAL IDENTIFICATIVA } \\
\hline
\end{tabular}

Seguidas das orações relacionais, temos, em segundo lugar, as orações mentais como mais recorrentes nos relatos pessoais, com $23 \%$. Esse índice pode ser explicado pelo fato de a temática girar em torno do "amor" e de as orações mentais construírem linguisticamente a experiência do mundo de nossa consciência (HALLIDAY; MATTHIESSEN, 2004; FUZER; CABRAL, 2014). O que novamente se destacou foi a forma como essas orações foram construídas. Os adolescentes aparecem como Experienciador em 58\% das orações mentais; porém, o Fenômeno dessas orações - o que é sentido, pensado, percebido ou desejado por eles - é o que chama a atenção. Em $70 \%$ das orações mentais, temos o "amor" como Fenômeno, sendo utilizados principalmente processos mentais perceptivos, indicando os momentos e as circunstâncias em que os jovens perceberam que estavam sendo amados, como pode ser visualizado no Exemplo 7 (E\#7).

\begin{tabular}{|c|c|c|c|c|}
\hline \multirow{3}{*}{ E\#7 } & A gente & Sente & amor & no olhar \\
\cline { 2 - 5 } & Experienciador & p. mental perceptivo & Fenômeno & Circunstância \\
\cline { 2 - 5 } & \multicolumn{4}{|c|}{ ORAÇÃO MENTAL PERCEPTIVA } \\
\hline
\end{tabular}

É importante ressaltar que o "amor", como processo mental emotivo, aparece somente em $6 \%$ das orações analisadas. A baixa ocorrência de "amar" como um processo mental pode ser explicada pela pouca experiência dos adolescentes em amar, e muito mais em sentirem-se amados. É possível que os adolescentes ainda não tenham expandido ou desenvolvido completamente sua rede afetiva, uma vez que poucos já conseguem desenvolver o papel de Experienciador do processo mental amar.

\section{Categorização dos resultados}

Através das análises de transitividade nos relatos pessoais, foi possível classificar o adolescente sob duas visões distintas: o de Recebedor, aquele que é afetado por esse Organon, Porto Alegre, v. 36, n. 71, p. 448-463, jan./jun. 2021. 
sentimento; e o de Amante, aquele que é responsável por amar algo ou alguém. De acordo com as análises realizadas, foi possível perceber que os adolescentes participantes encontramse mais no papel de Recebedor (56\%), sendo o amor recebido, na maioria das vezes, sinalizado como Fenômeno das orações mentais perceptivas, indicando que os jovens sentemse amados por outras pessoas. Em menor frequência, destacamos o segundo papel desempenhado pelo adolescente, o de Amante (44\%), em que ele é o responsável por amar algo ou alguém, resultado de ser o Experienciador das orações mentais emotivas. A Figura 4 tem como objetivo representar essa diferença de papéis desempenhados pelos adolescentes da presente pesquisa, trazendo breves exemplos dos relatos (R\#) dos adolescentes.

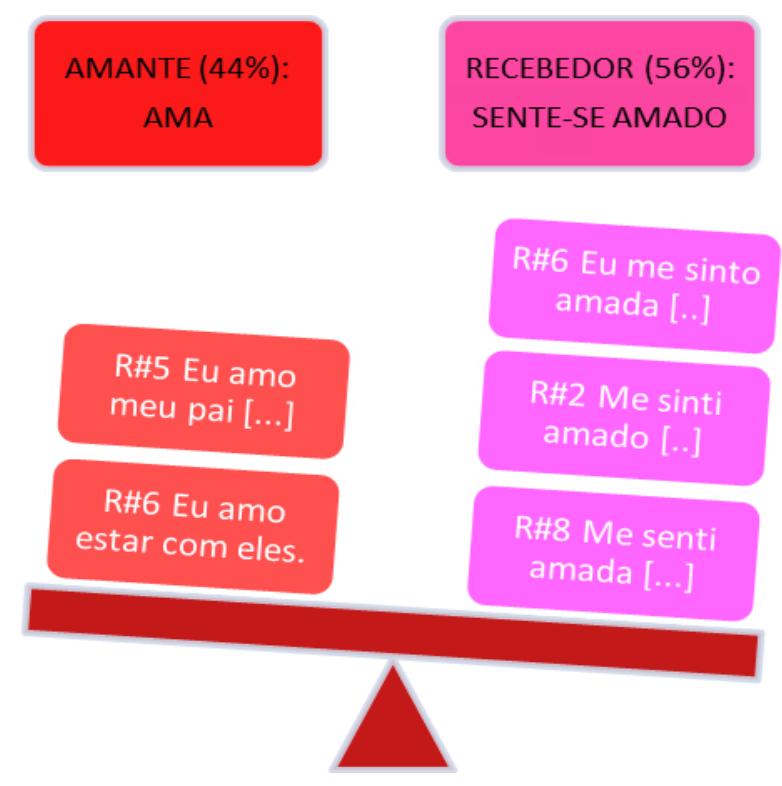

Figura 4 - Papel do adolescente no amor

Fonte: Elaborado pela autora

\section{Considerações finais}

Levando em conta a construção feita pelos alunos ao tentarem conceituar o amor por meio de orações encaixadas como identificador nas orações relacionais identificativas, podemos destacar o papel do professor de linguagem como o mediador necessário para que os jovens atinjam sua capacidade de desenvolver conceitos, atribuindo uma identidade específica ao fazerem uso de um nome ou grupo nominal. Tal mediação entre professor-aluno torna-se peça-chave no desenvolvimento das habilidades do adolescente, uma vez que, na escola, cabe ao profissional da educação percorrer o caminho daquilo que o aprendiz já sabe até o conhecimento que ele pode vir a saber. 
Com isso, temos as três zonas de desenvolvimento descritas por Vygotsky: a) zona de desenvolvimento real: o aluno consegue identificar o amor, porém o faz por meio de circunstâncias e processos; b) zona de desenvolvimento potencial: o aprendiz é capaz de desenvolver sua habilidade de conceituar por meio de nomes e grupos nominais; c) zona de desenvolvimento proximal: o professor de linguagem auxilia o aluno a alcançar tal objetivo.

Ainda com base nas escolhas léxico-gramaticais, foi possível identificar o papel do adolescente com o sentimento do amor. Em 56\% das orações mentais, temos o adolescente como Recebedor desse sentimento, uma vez que ele é apenas o Experienciador do Fenômeno amor, através de processos perceptivos. O adolescente assume o papel de Amante em 44\% das vezes, sendo ele o responsável por amar, realizado através de processos mentais emotivos. Os papéis assumidos aqui estão em consonância com a premissa de que é nessa fase da vida, na adolescência, que começam a se expandir os contextos nos quais os jovens estão inseridos - saindo do núcleo familiar, apropriando-se dos valores e significados partilhados, ressignificando-os - e, consequentemente, começando a assumir diferentes papéis que antes não lhes cabiam (OATLEY, 2004; XAVIER; NUNES, 2015).

Entretanto, vale salientar que os resultados obtidos são restritos ao contexto que os 25 participantes da pesquisa compartilham, residentes de uma cidade do interior do Rio Grande do Sul, estudantes de escola pública de ensino médio, com idades entre 17 e 18 anos. O número de participantes também é limitado, dando apenas um pequeno panorama do papel do adolescente diante do sentimento do amor. Como estudos futuros, propõe-se uma expansão no número de participantes dentro e fora desse contexto citado, para que seja possível ter uma visão mais ampla dos papéis assumidos no mundo atual e da relação do amor com a linguagem.

Com o que foi possível realizar nesta pesquisa, podemos reconhecer os traços linguísticos utilizados pelos participantes para dar conta dessa relação tão complexa entre os adolescentes e o sentimento do amor. Assim, além de dar luz a essa temática, espera-se contribuir para os estudos pautados pela Linguística Sistêmico-Funcional com foco nas emoções, uma vez que, como dito anteriormente, emoção e linguagem estão em conexão, sendo o sistema da emoção afetado pela performance da língua (BAMBERG, 1997). Vale ressaltar novamente que "as pessoas precisam e usam esse conhecimento para entender/interpretar suas próprias emoções e as dos outros, para interagir adequadamente e para interpretar a representação da experiência emocional” (BEDNAREK, 2008, p.148). 


\section{REFERÊNCIAS}

BAMBERG, Michael. Language, Concepts, and Emotions: The role of language in the construction of emotions. Language sciences, [s. l.], v. 19, n. 4, p. 309-340, 1997.

BEDNAREK, Monika. Emotion Talk Across Corpora. New York: Palgrave McMillan, 2008.

BUTT, D.; FAHEY, R.; FEEZ, S.; SPINKS, S.; YALLOP, C. Using functional grammar: An explorer's guide. Sydney: Macquarie University, $2^{\text {nd. }}$ ed, 2000.

DENZIN, Norman K.; LINCOLN, Yvonna. A disciplina e a pratica da pesquisa qualitativa. In: DENZIN, Norman K.; LINCOLN, Yvonna (orgs). Planejamento da pesquisa qualitativa: teorias e abordagens. 2. ed. Porto Alegre: ARTMED, 2006.

EGGINS, S. An Introduction to Systemic Functional Linguistics. 2nd ed. New York; London: Continuum, 2004.

FUZER, Cristiane; CABRAL, Sara R. S. Introdução à Gramática Sistêmico Funcional em língua portuguesa. São Paulo: Mercado de Letras, 2014.

GRANDE, Paula Bacarat, O pesquisador interpretativo e a postura ética em pesquisas em Linguística Aplicada. Eletras, [s. l.], vol. 23, n. 23, p. 11-27, dez. 2011.

HALLIDAY, Michael A. K. An introduction to functional grammar. London: Arnold, 1985.

HALLIDAY, Michael A. K. On grammar. v. 1. London: Continuum, 2002.

HALLIDAY, Michael A. K; MATTHIESSEN, Christian M. I. M. An introduction to functional grammar. 3rd ed. London: Arnold, 2004

HALLIDAY, Michael A. K; MATTHIESSEN, Christian M. I. M. Halliday's introduction to functional grammar. $4^{\text {th }}$ ed. London: Routledge, 2014.

HARLOW, Harry F. The nature of love. American Psychologist, Washington, DC, v. 13, n. 12, p. 673-685, 1958.

HEGI, Kevin. E; BERGNER, Raymond. M. What is love? An empirically-based essentialist account. Journal of Social and Personal Relationships, [s. l.], v. 27, n. 5, p. 620-636, 2010.

MARTIN, James R.; MATTHIESSEN, Christian M. I. M.; PAINTER, Clare. Deploying functional grammar. Beijing: The Commercial Press, 2010.

MOTTA-ROTH, Désirée; HENDGES, Graciela Rabuske. Produção textual na universidade. São Paulo: Parábola editorial, 2010.

OATLEY, Keith. Emotions: a brief history. Oxford: Blackwell Publisher, 2004.

OLIVEIRA, M. K. Vygotsky: Aprendizado e desenvolvimento - um processo sócio-histórico. São Paulo: Scipione, 1997. 
PAINTER, Clare. Developing attitude: an ontogenetic perspective on appraisal. Text, Australia, v. 23, n. 2, p. 183-209, 2003.

PAVENKOV, Oleg. S. Contemporary linguistic analysis of the concept "love". Studia Humanitates, Moscow, n. 4, 2014.

PLANALP, Sally. Communicating emotion: Social, moral and cultural processes. London: Cambridge University Press, 1999.

SANTOS, Zaíra. B. A Linguística Sistêmico-Funcional: algumas considerações. Soletras, Rio de Janeiro, n. 28, p.164-181, 2014.

SCHERER, Klaus. R. What are emotions? And how can they be measured? Social Science Information, [s. l.], v. 44, n. 4, p. 695-729, 2005.

TURNER, Jonathan. H. Human emotions: a sociological theory. New York: Routledge, 2007.

VYGOTSKY, Lev. S. A formação social da mente. São Paulo: Martins Fontes, 1984.

WILKINS, Richard; GAREIS, Elisabeth. Emotion expression and the locution "I love you": A cross-culture study. International Journal of Intercultural Relations, [s. l.], v. 30, p. 51-75, 2006.

XAVIER, Alessandra. S.; NUNES, Ana. I. B. L. Psicologia do desenvolvimento. Fortaleza: EdUECE, 2015. 